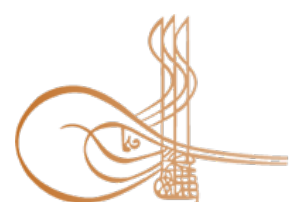

www.turkishstudies.net/social
Turkish Studies - Social Sciences

eISSN: 2667-5617

Research Article / Araștırma Makalesi

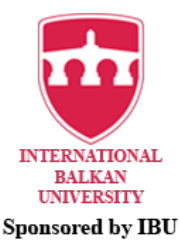

Sponsored by IBU

\title{
Serbest Zaman Engelleri ile Baş Etme Stratejileri: Üniversite Öğrencileri Örneği*
}

\author{
Leisure Negotation Strategies With the Leisure Constraints: Example of University Students
}

\author{
Cemal Güler $^{* *}$ - Duygu Harmandar Demirel ${ }^{* * *}$ - Veli Ozan Çakır ${ }^{* * *}$ - Davut Budak ${ }^{* * * *}$
}

\begin{abstract}
The aim of this study is to examine university students' participation in recreational activities and their strategies to cope with free time barriers in terms of different variables. While the university population constitutes the universe of the study, the sample group consists of 324 university students determined based on the principle of appropriate sampling and voluntary participation. In addition to the demographic data form as a data collection tool, Turkish adaptation for Turkish university students, developed by Hubbard and Mannell (2001), modified by Elkins (2004) to recreational campus sports, and validated by Beggs, Elkins and Powers (2005), is used by Yerlisu Lapa (2014) "Leisure Negotiation Strategies Scale" , which was carried out by. In the analysis of the data, percentage and frequency descriptive statistical methods were used to determine the distribution of the personal information of the participants, and the skewness and kurtosis values of the data were checked to determine whether the data showed a normal distribution. In addition, t-test and anova test analysis methods were used $(\alpha=0.05)$. According to the findings, it was determined that there was no significant difference in terms of age, welfare level, weekly leisure time adequacy variables, but there was a significant difference in participants skills acquisition strategies sub-dimension according to their gender, class, participation in sports activities and leisure time difficulties. Consequently, according to socio-demographic characteristics of university students, the obstacles they encounter in free time and their coping strategies may differ. Studies on how individuals should deal with free time barriers should increase as quantitative and qualitative methods. The limitations of the study and evaluations for future studies are discussed in this sense.
\end{abstract}

\footnotetext{
${ }^{*}$ Bu çalışma 2. Uluslararası 11-14 Nisan 2019 Rekreasyon ve Spor Yönetimi Kongresi’nde sözel bildiri olarak sunulmuştur ** Arş. Gör. İstanbul Üniversitesi-Cerrahpaşa, Spor Bilimleri Fakültesi, Spor Yöneticiliği Bölümü

R.A. Istanbul University-Cerrahpasa, Sports Sciences Faculty, Sports Management Department ORCID 0000-0001-6831-563X

cemal.guler@istanbul.edu.tr

*** Doç. Dr. Necmettin Erbakan Üniversitesi, Ahmet Keleşoğlu Eğitim Fakültesi, Beden Eğitimi ve Spor Bölümü

Assoc. Prof., Necmettin Erbakan University, Ahmet Kelesoglu Education Faculty, Physical Education and Sports

Department

ORCID 0000-0003-4090-7929

duyguharmandar@gmail.com

${ }_{* * * *}^{*}$ Doç. Dr., Alanya Alaaddin Keykubat Üniversitesi, Spor Bilimleri Fakültesi, Rekreasyon Bölümü

Assoc. Prof. Alaaddin Keykubat University, Sports Sciences Faculty, Recreation Department

ORCID 0000-0002-2072-5039

ozan.cakir@alanya.edu.tr

${ }^{* * * * *}$ Dr. Öğr. Üyesi. Atatürk Üniversitesi, Spor Bilimleri Fakültesi, Spor Yöneticiliği Bölümü

Asst. Prof. Dr. Atatürk University, Sports Sciences Faculty, Sports Management Department

ORCID 0000-0003-2632-0232

dbudak@atauni.edu.tr

Cite as/ Atıf: Güler, C., Harmandar Demirel, D., Çakır, V. O., Budak, D. (2020). Serbest zaman engelleri ile baş etme stratejileri: Üniversite öğrencileri örneği. Turkish Studies - Social, 15(4), 1919-1930. https://dx.doi.org/10.29228/TurkishStudies.43508

Received/Geliș: 11 May/Mayıs 2020

Accepted/Kabul: 20 June/Haziran 2020

Copyright (C) INTAC LTD, Turkey

Checked by plagiarism software

Published/Yaym: 25 June/Haziran 2020

CC BY-NC 4.0
} 
Structured Abstract: Technological developments and mechanization gave people more free time (Ustun, 2013; Cuhadar et al., 2019). Participation in leisure activities that affect human life both physically, psychologically and socially is affected by many factors (Lapa \& Kose, 2018). One of the most important factors affecting this situation is leisure time barriers and strategies to deal with these barriers. The purpose of working with this information; It is aimed at determining university students' strategies to cope with free time barriers in the light of variables such as gender, welfare level, class, and leisure time.

The universe of the research is individuals who study at university. Participants to be included in the sample were taken using the appropriate sampling method and the sample group; A total of 324 university students constitute 81 women (25\%) and 243 men (75\%). In the study; by Hubbard \& Mannelli (2001) in the developed later in Elkins (2004), adapted by the recreational campus sports and still Beggs, Elkins \& Powers (2005) Validity made native Lapa this scale for university students in Turkey (2014) by adapted form as "Scale of Coping Strategies with Free Time Barriers". In the analysis of the data, percentage and frequency descriptive statistical methods were used to determine the distribution of the personal information of the participants, and the skewness and kurtosis values of the data were checked to determine whether they show normal distribution. In addition, $t$-test and anova test analysis methods were used $(\alpha=0.05)$.

While no significant difference could be determined according to the age, welfare level, weekly free time adequacy variables of the participants, a significant difference was found in the sub-dimension of skills acquisition strategies according to the participants' gender, class, participation in sports activities and having difficulty in leisure time assessment. Limitations of the study and evaluations for future studies are discussed in this sense.

The aim of this study is to examine the factors that prevent university students from participating in recreational activities and coping strategies according to various demographic variables.

$75 \%$ of the sample group determined for this purpose is Male, 55.2\% are in the $21-25$ age group, $42.0 \%$ are 1 st year students, $53.7 \%$ have Normal well-being, $84 \%$ It is determined that fame is sports, $47 \%$ of them have normal weekly leisure time and $70.7 \%$ of them sometimes have difficulty in evaluating their spare time.

When the strategies of coping with leisure time barriers according to the gender variable of the participants were examined, it was determined that there was a significant difference only in the sub-dimension of "Skill Acquisition Strategies". It was concluded that this significant difference originated from male participants and that male participants were able to cope better with free time barriers in the "Skill Acquisition Strategies" sub-dimension compared to female participants. However, Koca et al. (2009) reached the conclusion that family responsibilities, which are one of the interpersonal obstacles, affect women's free time participation in their studies in which women in the Turkish society examine the obstacles and their strategies to cope with them. In addition, contrary to our findings, in the study conducted by Karaca \& Lapa (2016), it was concluded that gender is not a variable that makes a significant difference in free time barriers and coping strategies.

According to the results of the analysis performed according to the participants' sports status, it was determined that the individuals doing sports showed a significant difference according to the sub-dimension of "Skill Acquisition Strategies" and the total score of the scale. According to the age variable, there was no significant difference between the leisure time barriers and coping strategies of the participants. This result, Ayhan et al. (2018) does not show parallelism with the findings of their research on free time satisfaction. However, Güler et al. In the study conducted by (2019) on students of physical education and sports school, similarly with our study, there was no significant difference between free time barriers and age.

While no significant difference could be determined between leisure time barriers and coping strategies and welfare level in the research, Gratton (2000) stated that the most important factor in the recreational participation of the individual was "money". Another important result in our study was that there was a significant difference only in the sub-dimension of "Skill Acquisition Strategies" in the scores of leisure assessment difficulties and the scale of coping strategies with leisure time $(p<0.05)$.

With this result, it can be interpreted that individuals who do not have difficulty in evaluating free time can develop their strategies to cope with free time barriers in sub-dimensions other than skill acquisition strategies. As a result, the obstacles faced in their free time and their strategies to cope may differ according to 
gender, class, participation in sports activities and leisure time difficulties, that is, socio demographic characteristics. It can be said that there are more differences especially in terms of sports and leisure time difficulties. Studies on individuals' strategies to cope with free time barriers should be analyzed qualitatively in detail.

Keywords: Recreation, Leisure, Negotiation Strategies

Öz: Bu çalışmanın amacı üniversite öğrencilerinin rekreasyonel aktivitelere katılımları ile serbest zaman engelleriyle baş etme stratejilerinin farklı değişkenler açısından incelenmesidir. Çalı̧̧manın evrenini üniversite öğrencileri oluştururken örneklem grubunu uygun örnekleme ve gönüllü katılım ilkesine bağlı olarak belirlenmiş 324 üniversite öğrencisi oluşturmaktadır. Veri toplama aracı olarak demografik veri formuna ilave olarak Hubbard ve Mannell (2001) tarafindan geliştirilen, Elkins (2004) tarafindan rekreasyonel kampüs sporlarına modifiye edilen ve Beggs, Elkins ve Powers (2005) tarafindan geçerliği doğrulanan, Türk üniversite öğrenciler için Türkçe adaptasyonu Yerlisu Lapa (2014) tarafindan gerçekleştirilmiş olan "Serbest Zaman Engelleri ile Baş Etme Stratejileri Ölçeği" kullanılmışır. Verilerin analizinde katılımcıların kişisel bilgilerinin dağılımlarını belirlemek için yüzde ve frekans tanımlayıcı istatistik yöntemleri, verilerin normal dağılım gösterip göstermediğini belirlemek için verilerin çarpıklık ve basıklık değerleri kontrol edilmiştir. Ayrıca ttesti ve anova testi analizi yöntemleri kullanılmıştır $(\alpha=0.05)$. Bulgulara göre katılımcıların yaş, refah düzeyi, haftalık boş zaman süresi yeterliği değişkenlerine göre anlamlı farklılık belirlenemezken, katılımcıların cinsiyet, sınıf, sportif etkinliklere katılım durumu ve boş zaman değerlendirme güçlüğü çekme durumlarına göre beceri kazanma stratejileri alt boyutunda anlamlı farklılık olduğu tespit edilmiş̧ir. Sonuç olarak üniversite öğrencilerinin sosyo demografik özelliklere göre serbest zamanda karşılaştıları engeller ile baş etme stratejileri farklılık gösterebilmektedir. Bireylerin serbest zaman engelleriyle nasıl baş etmesi gerektiği ile ilgili çalışmaların nicel ve nitel yöntemler olarak artması gerekmektedir. Çalışmanın sınırlılıkları ve gelecek çalışmalara yönelik değerlendirmeler bu anlamda tartışılmıştır.

Anahtar Kelimeler: Rekreasyon, Serbest Zaman, Baş Etme Stratejileri

\section{Giriş}

İnsanoğlu, yeryüzünde var olmaya başladığı çağlardan günümüze kadar, bedensel ve ruhsal sınırlarını aşmaya çalışmış, yetenek ve becerilerini geliştirmeye uğraşmış, bu gibi becerilerin geliştirilmesi için de serbest zaman etkinlikleri bir araç olmuştur (Songün vd., 2015). Bu sayede bireylerin serbest zamanlarını değerlendirmek için çeşitlilik arz eden, hizmet sunan canlı bir sektörün oluşması sağlanmıştır. Ekonomik verimliliğin artmasıyla beraber insanların çalışma şartlarının da iyileşmesiyle ortaya çıkan serbest zamanın bilinçli değerlendirilmesi, pozitif sonuçlar doğuracak bütünsel bir çaba olmalıdır (Özdilek vd., 2007; Demirel \& Harmandar, 2009).

Rekreasyonel faaliyetler, bireyin gün içinde karşılaşmak zorunda kaldığı psikolojik ve fizyolojik sorunların üstesinden gelmek ve organizmayı sağlıklı ve dinç tutmak için önemli bir rol oynamaktadır (Rhodes \& Dean, 2009; Güngörmüş vd., 2014). Çünkü Rekreasyon katılımcıların psikolojik ve fiziksel yenilenmesini ifade eder (Sarol \& Çimen, 2017). Yaşam boyu gelişim süreçlerine yönelik destek unsuru olarak kabul edilen (Gürbüz ve Henderson, 2014) serbest zaman kavramı, bireylerin özgürce kendilerini ifade ettikleri bir zaman dilimi olarak ifade edilmektedir (Kara vd., 2018; Er vd., 2019).

Üniversite öğrenciliği dönemi de bu dönemlerden birisidir. Üniversite döneminde birey, kimlik bulma, toplumun ulusal ve evrensel değerlerini benimseme, uyum sağlama, ekonomik, sosyal eve akademik olarak sorumluluklar alma ve bununla birlikte olgunluğa erişme süreçlerini yaşadığını ifade edebiliriz. Bu ifade ettiğimiz zorlu süreçte üniversite öğrencilerinin psikolojik olarak sağlıklarına etki eden ve onların yaşamdan aldıkları doyumu etkileyen çeşitli değişkenleri göz önünde bulundurarak çalışmaların yapılması önem arz etmektedir. Bu araştırmalar aynı zamanda 
öğrencilerin psikolojik, sosyolojik ve fiziksel ihtiyaçlarını karşılaması yanında, yaşamdan aldıkları doyumu da arttırmaya yönelik olması gerekmektedir (Tel \& Sarı, 2016; Soyer vd., 2017).

Günümüzde, teknolojik gelişmeler ve makineleşme, insanlara daha çok serbest zaman kazandırmıştır (Üstün, 2013; Çuhadar vd., 2019). Serbest zaman etkinlikleri insan hayatını sosyal, psikolojik ve fiziksel olarak olumlu etkilemekte diğer yandan birçok faktör tarafindan etkilenmektedir (Lapa \& Köse, 2018). Bu durumu etkileyen en önemli faktörlerden biri de serbest zaman engelleri ve bu engeller ile başa çıkma stratejileridir. Serbest zaman engelleri, kişinin serbest zaman aktivitelerine katılmasını engelleyen veya katılmasına etki eden olumlu duyguların azalmasına sebep olan faktörler olarak tanımlanmaktadır (Jackson \& Scott, 1999). Baş etme stratejisi kavramı ise, bireylerin serbest zaman engellerini aşmak ve engellemek için ortaya koyduğu stratejiler sonucunda ortaya çıkmıştır (Güler vd., 2019).

Bireyler herhangi bir serbest zaman etkinliğine katılırken engellerle karşılaşmış olmalarına rağmen bazıları bu engelleri aşarak istedikleri etkinliğe katılım sağlayabilmişlerdir. Genel olarak baş etme kavramı, bireyin serbest zaman etkinliklerine katılırken karşılaşmış olduğu engeller ile düzenli bir şekilde baş ederek bu engelleri aşma, azaltma ya da adapte olma yeteneğidir (Crawford vd., 1991; Lapa \& Köse, 2018). Bu doğrultuda bireyin yaşantısından tatmin olamama durumu birçok literatür kaynaklarında da belirtildiği gibi serbest zaman kavramının kısıtlanması veya engellenmesiyle ortaya çıkabilmektedir. Bireyin maksimum duygu düzeyine ulaşması serbest zamanlarının engellerinin düşük olması veya bireyin bu engellerle baş etme yeteneğinin yüksek olmasına bağlıdır (Karaca \& Lapa, 2016).

$\mathrm{Bu}$ bilgilerden hareketle çalı̧̧manın amacı; üniversite öğrencilerinin cinsiyet, refah düzeyi, sınıf, boş zaman süresi gibi değişkenler 1şı̆̆ında serbest zaman engelleriyle baş etme stratejilerinin belirlenmesine yöneliktir.

\section{Yöntem}

Araştırmanın evrenini üniversitede öğrenim gören bireyler oluşturmaktadır. Uygun örneklem yöntemi kullanılarak çalışmaya dahil edilen katılımcıların \%25'i (81) Kadın, ve \%75'i Erkek olmak üzere toplam 324 üniversite öğrencisidir. Çalışmada Hubbard ve Mannell tarafindan (2001) yılında geliştirilmiş, daha sonra Elkins (2004) tarafından rekreasyonel amaçlı kampüs sporlarına adapte edilen ve yine Beggs ve Powers (2005) tarafından geçerliği yapılmış bu ölçek Türkiye'de üniversite öğrencilerine yönelik olarak Yerlisu Lapa (2014) tarafından "Serbest Zaman Engelleri ile Baş Etme Stratejileri" olarak uyarlanmıştır. Ölçeğin orjinaline bakıldığında 31 madde ve altı alt boyuttan olmuşmaktadır. Alt boyutlar sırasıyla, Zaman Yönetimi Stratejileri, Beceri Kazanma Stratejileri, Kişilerarası İlişkiler, İçsel Onaylama Stratejileri, Fiziksel Uygunluk Stratejileri ve Finansal Yönetimden oluşmaktadır. Ölçeğin hesaplanması 1 ile 5 puan arasında 1 "Asla", 5 ise "Çok sık" olarak değerlendirilmektedir. Ölçeğin iç tutarlılık kat sayısı 6 alt boyutta .70 ve .77 arasında değişmekte, ölçeğine geneline bakıldığında ise .81 bulunmuştur (Yerlisu Lapa, 2014). Bu çalışma için ise alt boyutlara ilişkin iç tutarlı1ık katsayıları .82 ile .85 arasında değişirken, ölçeğin geneline ilişkin .79 olarak saptanmıştır.

Çalışmada veriler elde edilirken katılımcıların demografik bilgilerinin dağılımını belirlemek için tanımlayıcı (yüzde ve frekans) yöntemleri kullanılmıştır. Verilerin normallik değerini tespit etmek için çarpıklık ve basıklık değerleri tespit edilerek Kolmogorov Smirnov testi uygulanmıştır. Bunun sonucunda verilerin normal dağıldığ 1 belirlenmiştir. Jondeau ve Rockinger (2003), alt boyutların çarpıklık ve basıklık değerleri +3 ile -3 arasından değiştiğinden dolayı, bu alt boyutlarında normal dağılım parametrelerine uygun koşullar taşıdığını ifade etmektedir. Aynı zamanda tanımlayıcı istatistiklerin yanında Anova ve T-testi analiz yöntemleri de kullanılmıştır $(\alpha=0.05)$. 


\section{Bulgular}

Tablo 1: Serbest Zaman Engelleri İle Baş Etme Stratejileri Ölçeği (SZEBSÖ) Toplam Puan ve Alt Boyutlarına İlişkin İç Tutarlık Katsayıları

\begin{tabular}{lc}
\hline Alt Boyutlar & Mevcut Çalş̧ma \\
\hline Ölçek Toplam & .794 \\
\hline Zaman Yönetimi & .853 \\
\hline Beceri Kazanma Str. & .830 \\
\hline Kişilerarası İlişkiler & .830 \\
\hline İçel Onaylama Str. & .848 \\
\hline Fiziksel Uygunluk Str. & .834 \\
\hline Finansal Yönetim & .820 \\
\hline
\end{tabular}

Tablo 1'de çalışma kapsamındaki katılımcıların, Serbest Zaman Engelleri İle Baş Etme Stratejileri Ölçeği (SZEBSÖ) ölçeği toplam puan ve alt boyutlarına ilişkin iç tutarlık katsayıları verilmiştir. Buna göre en yüksek iç tutarlık katsayısı .853 ile "Zaman Yönetimi" alt boyutunda belirlenmiştir.

Tablo 2. Serbest Zaman Engelleri İle Baş Etme Stratejileri Ölçeği (SZEBSÖ)

Toplam Puan ve Alt Boyut Puanlarının Dağılımı

\begin{tabular}{lllllll}
\hline Ölçek ve Alt Boyutlar & $\begin{array}{l}\text { Madde } \\
\text { Sayısı }\end{array}$ & N & Ort. & Ss & Çarpıklık & Basıklık \\
\hline Ölçek Toplam & 27 & 324 & 3,38 &, 551 &,- 764 & 1,461 \\
\hline Zaman Yönetimi & 6 & 324 & 3,00 &, 703 &, 242 &, 508 \\
\hline Beceri Kazanma Str. & 5 & 324 & 3,72 &, 818 &,- 731 &, 543 \\
\hline Kişilerarası İlişkiler & 5 & 324 & 3,28 &, 730 &,- 438 &, 575 \\
\hline İçsel Onaylama Str. & 3 & 324 & 3,34 &, 876 &,- 529 &, 128 \\
\hline Fiziksel Uygunluk Str. & 3 & 324 & 3,60 &, 945 &,- 702 &, 467 \\
\hline Finansal Yönetim & 5 & 324 & 3,47 &, 736 &,- 555 &, 782 \\
\hline
\end{tabular}

Tablo 2'de çalışma kapsamındaki katılımcıların, Serbest Zaman Engelleri İle Baş Etme Stratejileri Ölçeği (SZEBSÖ) ölçeği toplam puan ve alt boyutlarına ilişkin aldıkları puanların ortalamaları verilmiştir. Buna göre en yüksek ortalama 3.72 ile "Beceri Kazanma Stratejileri”" alt boyutunda belirlenmiştir.

Tablo 3. Kat1lımcıların Demografik Bilgileri

\begin{tabular}{|c|c|c|c|}
\hline & Değișkenler & $\mathbf{F}$ & $\%$ \\
\hline \multirow{3}{*}{ Cinsiyet } & Kadın & 81 & 25,0 \\
\hline & Erkek & 243 & 75,0 \\
\hline & Toplam & 324 & 100,0 \\
\hline \multirow{4}{*}{ Yaş } & 17-20 Yaş & 127 & 39,2 \\
\hline & 21-25 Yaş & 179 & 55,2 \\
\hline & 26 ve Üstü & 18 & 5,6 \\
\hline & Toplam & 324 & 100,0 \\
\hline \multirow{6}{*}{ Sinif } & 1. Sinif & 136 & 42,0 \\
\hline & 2. Sinif & 76 & 23,5 \\
\hline & 3. Sinif & 49 & 15,1 \\
\hline & 4. Sinif & 63 & 19,4 \\
\hline & Toplam & 324 & 100,0 \\
\hline & Çok Kötü & 17 & 5,2 \\
\hline
\end{tabular}




\begin{tabular}{|c|c|c|c|}
\hline \multirow{5}{*}{ Refah Düzeyi } & Kötü & 38 & 11,7 \\
\hline & Normal & 174 & 53,7 \\
\hline & İyi & 75 & 23,1 \\
\hline & Çok İyi & 20 & 6,2 \\
\hline & Toplam & 324 & 100,0 \\
\hline \multirow{3}{*}{ Spor Yapıyormusunuz? } & Evet & 272 & 84,0 \\
\hline & Hayır & 52 & 16,0 \\
\hline & Toplam & 324 & 100,0 \\
\hline \multirow{6}{*}{$\begin{array}{l}\text { Haftalık Boş Zaman } \\
\text { Süresinin Yeterliği }\end{array}$} & Kesinlikle Yetersiz & 15 & 4,6 \\
\hline & Yetersiz & 40 & 12,3 \\
\hline & Normal & 153 & 47,2 \\
\hline & Yeterli & 91 & 28,1 \\
\hline & Kesinlikle Yeterli & 25 & 7,7 \\
\hline & Toplam & 324 & 100,0 \\
\hline \multirow{4}{*}{$\begin{array}{l}\text { Boş Zamanlarnızı } \\
\text { Değerlendirmekte Ne Sıklıkla } \\
\text { Güçlük Çekiyorsunuz? }\end{array}$} & Her Zaman & 27 & 8,3 \\
\hline & Bazen & 229 & 70,7 \\
\hline & Hiçbir Zaman & 68 & 21,0 \\
\hline & Toplam & 324 & 100,0 \\
\hline
\end{tabular}

Tablo 3' de görüldüğü gibi, araştırma kapsamında yer alan katılımcıların \%75'inin Erkek, $\% 55,2$ ' sinin 21-25 yaş grubunda olduğu, \%42,0'ının 1. Sınıf öğrencisi olduğu, \%53.7'sinin Normal refah düzeyine sahip olduğu, \%84'ünün spor yaptığ1, \%47'sinin normal haftalık boş zaman süresine sahip olduğu ve \%70.7'sinin boş zamanlarını değerlendirirken bazen güçlük çektiği belirlenmiştir.

Tablo 4. Cinsiyet Değişkenine Göre Katılımcıların Serbest Zaman Engelleri İle Baş Etme Stratejileri Ölçeği (SZEBSÖ) Puanları

\begin{tabular}{|c|c|c|c|c|c|}
\hline Alt Boyutlar & Değişken & $\mathbf{N}$ & Ortalama & $\mathbf{T}$ & $\mathbf{P}$ \\
\hline \multirow[t]{2}{*}{ Ölçek Toplam Puan } & Kadın & 81 & 3,41 & 562 & ,575 \\
\hline & Erkek & 243 & 3,37 & & \\
\hline \multirow[t]{2}{*}{ Zaman Yönetimi } & Kadın & 81 & 2,96 &,- 569 & 5,570 \\
\hline & Erkek & 243 & 3,01 & & \\
\hline \multirow[t]{2}{*}{ Beceri Kazanma Str. } & Kadın & 81 & 3,88 & ,200* & ,046 \\
\hline & Erkek & 243 & 3,67 & & \\
\hline \multirow[t]{2}{*}{ Kişilerarası İlişkiler } & Kadın & 81 & 3,25 &,- 360 & ,719 \\
\hline & Erkek & 243 & 3,29 & & \\
\hline \multirow[t]{2}{*}{ İçsel Onaylama Str. } & Kadın & 81 & 3,38 & 4,414 & ,679 \\
\hline & Erkek & 243 & 3,33 & & \\
\hline \multirow{2}{*}{ Fiziksel Uygunluk Str. } & Kadın & 81 & 3,63 & ,327 & ,744 \\
\hline & Erkek & 243 & 3,59 & & \\
\hline \multirow[t]{2}{*}{ Finansal Yönetim } & Kadın & 81 & 3,51 & 5,514 & ,608 \\
\hline & Erkek & 243 & 3,46 & & \\
\hline
\end{tabular}

\section{${ }^{*} \mathbf{p}<\mathbf{0 . 0 5}$}

Tablo 4'de Bağımsız Örneklem T-Testi sonuçlarına göre; katılımcıların cinsiyetleri ile Serbest Zaman Engelleri İle Baş Etme Stratejileri Ölçeği (SZEBSÖ) "Beceri Kazanma Stratejileri" alt boyutunda anlamlı farklılık olduğu belirlenirken $(p<0.05)$; diğer alt boyut puanları arasında anlamlı farklılık olmadığ 1 tespit edilmiştir $(\mathrm{p}>0.05)$. Kadın katılımcıların ortalama puanları erkek katılımcılardan daha yüksek bulunmuştur. 
Tablo 5. Spor Yapma Durumu Değişkenine Göre Katılımcıların Serbest Zaman Engelleri İle Baş Etme Stratejileri Ölçeği (SZEBSÖ) Puanları

\begin{tabular}{|c|c|c|c|c|c|}
\hline Alt Boyutlar & Değişken & $\mathbf{N}$ & Ortalama & $\mathbf{T}$ & $\mathbf{P}$ \\
\hline \multirow[t]{2}{*}{ Ölçek Toplam Puan } & Evet & 272 & 3,41 & $2.038^{*}$ & ,042 \\
\hline & Hayır & 52 & 3,24 & & \\
\hline \multirow[t]{2}{*}{ Zaman Yönetimi } & Evet & 272 & 3,00 & ,099 & 921 \\
\hline & Hayır & 52 & 2,99 & & \\
\hline \multirow[t]{2}{*}{ Beceri Kazanma Str. } & Evet & 272 & 3,78 & 3.091* & ,002 \\
\hline & Hayır & 52 & 3,41 & & \\
\hline \multirow{2}{*}{ Kişilerarası İliş̧kiler } & Evet & 272 & 3,30 & 1,244 & 214 \\
\hline & Hayır & 52 & 3,16 & & \\
\hline \multirow[t]{2}{*}{ İçsel Onaylama Str. } & Evet & 272 & 3,36 & ,589 & ,556 \\
\hline & Hayır & 52 & 3,28 & & \\
\hline \multirow[t]{2}{*}{ Fiziksel Uygunluk Str. } & Evet & 272 & 3,64 & 1,758 & ,080 \\
\hline & Hayır & 52 & 3,39 & & \\
\hline \multirow[t]{2}{*}{ Finansal Yönetim } & Evet & 272 & 3,50 & 1,694 & ,091 \\
\hline & Hayır & 52 & 3,31 & & \\
\hline
\end{tabular}

\section{$* \mathbf{p}<\mathbf{0 . 0 5}$}

Tablo 5'de Bağımsız Örneklem T-Testi sonuçlarına göre; katılımcıların spor yapma durumu ile Serbest Zaman Engelleri İle Baş Etme Stratejileri Ölçeği (SZEBSÖ) "Beceri Kazanma Stratejileri”" alt boyutunda ve ölçek toplam puanında anlamlı farklılık olduğu belirlenirken $(p<0.05)$, diğer alt boyut puanları arasında anlamlı farklı1ık olmadığ 1 tespit edilmiştir ( $>0.05)$.

Tablo 6. Yaş Değiş̧kenine Göre Katılımcıların Serbest Zaman Engelleri İle

Baş Etme Stratejileri Ölçeği (SZEBSÖ) Puanları

\begin{tabular}{|c|c|c|c|c|c|}
\hline Ölçek & Değişken & Ort. & Ss & $\mathbf{F}$ & $\mathbf{P}$ \\
\hline \multirow[t]{3}{*}{ Ölçek Toplam Puan } & $17-20$ & 3,42 & ,536 & \multirow{3}{*}{, 552} & \multirow{3}{*}{, 576} \\
\hline & $21-25$ & 3,35 & ,563 & & \\
\hline & 26 ve Üzeri & 3,40 & ,544 & & \\
\hline \multirow[t]{3}{*}{ Zaman Yönetimi } & $17-20$ & 3,02 & 690 & \multirow{3}{*}{,402 } & \multirow{3}{*}{,669 } \\
\hline & $21-25$ & 2,97 & ,696 & & \\
\hline & 26 ve Üzeri & 3,11 & ,880 & & \\
\hline \multirow{3}{*}{$\begin{array}{l}\text { Beceri Kazanma } \\
\text { Stratejileri }\end{array}$} & $17-20$ & 3,76 & ,858 & \multirow{3}{*}{,619 } & \multirow{3}{*}{, 539} \\
\hline & $21-25$ & 3,68 & ,796 & & \\
\hline & 26 ve Üzeri & 3,87 & ,767 & & \\
\hline \multirow[t]{3}{*}{ Kişilerarası İlişkiler } & $17-20$ & 3,32 & ,698 & \multirow{3}{*}{,387 } & \multirow{3}{*}{ 679 } \\
\hline & $21-25$ & 3,25 & ,751 & & \\
\hline & 26 ve Üzeri & 3,25 & ,766 & & \\
\hline \multirow{3}{*}{$\begin{array}{l}\text { İçsel Onaylama } \\
\text { Stratejileri }\end{array}$} & $17-20$ & 3,40 & 887 & \multirow{3}{*}{,473 } & \multirow{3}{*}{,624 } \\
\hline & $21-25$ & 3,30 & ,878 & & \\
\hline & 26 ve Üzeri & 3,31 & ,804 & & \\
\hline \multirow{3}{*}{$\begin{array}{l}\text { Fiziksel Uygunluk } \\
\text { Stratejileri }\end{array}$} & $17-20$ & 3,67 & ,917 & \multirow{3}{*}{1,289} & \multirow{3}{*}{ 277 } \\
\hline & $21-25$ & 3,59 & ,938 & & \\
\hline & 26 ve Üzeri & 3,29 & 1,187 & & \\
\hline \multirow[t]{3}{*}{ Finansal Yönetim } & $17-20$ & 3,49 & ,705 & \multirow{3}{*}{272} & \multirow{3}{*}{,762 } \\
\hline & $21-25$ & 3,45 & ,757 & & \\
\hline & 26 ve Üzeri & 3,56 & ,755 & & \\
\hline
\end{tabular}


Tablo 6' da ANOVA testine göre katılımcıların yaşları ile Serbest Zaman Engelleri İle Baş Etme Stratejileri Ölçeği (SZEBSÖ) puanlarında anlamlı farklılık olmadığı ortaya çıkmıştır $(\mathrm{p}>0.05)$.

Tablo 7. Refah Düzeyi Değişkenine Göre Katılımcıların Serbest Zaman Engelleri İle Baş Etme Stratejileri Ölçeği (SZEBSÖ) Puanları

\begin{tabular}{|c|c|c|c|c|c|}
\hline Ölçek & Değişken & Ort. & Ss & $\mathbf{F}$ & $\mathbf{P}$ \\
\hline \multirow{5}{*}{ Ölçek Toplam Puan } & Çok Kötü & 3,26 & ,636 & \multirow{5}{*}{, 767} & \multirow{5}{*}{, 547} \\
\hline & Kötü & 3,39 &, 381 & & \\
\hline & Normal & 3,35 & ,521 & & \\
\hline & İyi & 3,46 & ,639 & & \\
\hline & Çok İyi & 3,39 & ,646 & & \\
\hline \multirow[t]{5}{*}{ Zaman Yönetimi } & Çok Kötü & 2,98 &, 796 & \multirow{5}{*}{, 220} & \multirow{5}{*}{,927 } \\
\hline & Kötü & 3,00 &, 592 & & \\
\hline & Normal & 2,98 & ,642 & & \\
\hline & İyi & 3,07 &, 845 & & \\
\hline & Çok İyi & 3,00 & ,796 & & \\
\hline \multirow{5}{*}{$\begin{array}{l}\text { Beceri Kazanma } \\
\text { Stratejileri }\end{array}$} & Çok Kötü & 3,77 & 670 & \multirow{5}{*}{,606 } & \multirow{5}{*}{,659 } \\
\hline & Kötü & 3,66 & 571 & & \\
\hline & Normal & 3,68 &, 830 & & \\
\hline & İyi & 3,83 & ,890 & & \\
\hline & Çok İyi & 3,82 & ,968 & & \\
\hline \multirow[t]{5}{*}{ Kişilerarası İlişkiler } & Çok Kötü & 2,97 & ,910 & \multirow{5}{*}{1,438} & \multirow{5}{*}{,221 } \\
\hline & Kötü & 3,30 &, 578 & & \\
\hline & Normal & 3,25 & ,661 & & \\
\hline & İyi & 3,40 &, 870 & & \\
\hline & Çok İyi & 3,35 & ,786 & & \\
\hline \multirow{5}{*}{$\begin{array}{l}\text { İçsel Onaylama } \\
\text { Stratejileri }\end{array}$} & Çok Kötü & 3,11 & 1,013 & \multirow{5}{*}{,972 } & \multirow{5}{*}{,423 } \\
\hline & Kötü & 3,56 &, 849 & & \\
\hline & Normal & 3,35 &, 752 & & \\
\hline & $\begin{array}{l}\text { İyi } \\
\end{array}$ & 3,28 & 1,031 & & \\
\hline & Çok İyi & 3,33 & 1,159 & & \\
\hline \multirow{5}{*}{$\begin{array}{l}\text { Fiziksel Uygunluk } \\
\text { Stratejileri }\end{array}$} & Çok Kötü & 3,11 &, 865 & \multirow{5}{*}{1,841} & \multirow{5}{*}{,121 } \\
\hline & Kötü & 3,57 & ,902 & & \\
\hline & Normal & 3,60 &, 952 & & \\
\hline & İyi & 3,77 & ,952 & & \\
\hline & Çok İyi & 3,50 & ,927 & & \\
\hline \multirow[t]{5}{*}{ Finansal Yönetim } & Çok Kötü & 3,54 & ,757 & \multirow{5}{*}{, 423} & \multirow{5}{*}{,792 } \\
\hline & Kötü & 3,49 & 628 & & \\
\hline & Normal & 3,43 &, 719 & & \\
\hline & İyi & 3,56 & ,821 & & \\
\hline & Çok İyi & 3,44 & ,747 & & \\
\hline
\end{tabular}


Tablo 7'de ANOVA testine göre katılımcıların refah düzeyleri ile Serbest Zaman Engelleri İle Baş Etme Stratejileri Ölçeği (SZEBSÖ) puanlarında anlamlı farklılık olmadığı belirlenmiştir $(\mathrm{p}>0.05)$.

Tablo 8. Boș Zaman Değerlendirme Güçlüğü Çekme Durumu Değişkenine Göre Katılımcıların Serbest Zaman Engelleri İle Baş Etme Stratejileri Ölçeği (SZEBSÖ) Puanları

\begin{tabular}{|c|c|c|c|c|c|}
\hline Ölçek & Değişken & Ort. & Ss & $\mathbf{F}$ & $\mathbf{P}$ \\
\hline \multirow[t]{3}{*}{ Ölçek Toplam Puan } & Her Zaman & 3,27 & ,469 & \multirow{3}{*}{1,678} & \multirow{3}{*}{, 188} \\
\hline & Bazen & 3,36 & ,564 & & \\
\hline & Hiçbir Zaman & 3,47 &, 528 & & \\
\hline \multirow[t]{3}{*}{ Zaman Yönetimi } & Her Zaman & 3,09 & ,606 & \multirow{3}{*}{,262 } & \multirow{3}{*}{, 770} \\
\hline & Bazen & 2,99 & ,664 & & \\
\hline & Hiçbir Zaman & 3,00 & 858 & & \\
\hline \multirow{3}{*}{$\begin{array}{l}\text { Beceri Kazanma } \\
\text { Stratejileri }\end{array}$} & Her Zaman & 3,47 & ,649 & \multirow{3}{*}{$6,257^{*}$} & \multirow{3}{*}{,002 } \\
\hline & Bazen & 3,67 & ,846 & & \\
\hline & Hiçbir Zaman & 4,01 & ,713 & & \\
\hline \multirow[t]{3}{*}{ Kişilerarası İlişkiler } & Her Zaman & 3,30 & ,711 & \multirow{3}{*}{, 029} & \multirow{3}{*}{,971 } \\
\hline & Bazen & 3,28 & ,709 & & \\
\hline & Hiçbir Zaman & 3,26 & ,813 & & \\
\hline \multirow{3}{*}{$\begin{array}{l}\text { İçsel Onaylama } \\
\text { Stratejileri }\end{array}$} & Her Zaman & 3,04 & 1,142 & \multirow{3}{*}{1,713} & \multirow{3}{*}{, 182 } \\
\hline & Bazen & 3,37 & ,839 & & \\
\hline & Hiçbir Zaman & 3,37 & ,873 & & \\
\hline \multirow{3}{*}{$\begin{array}{l}\text { Fiziksel Uygunluk } \\
\text { Stratejileri }\end{array}$} & Her Zaman & 3,34 & 931 & \multirow{3}{*}{1,406} & \multirow{3}{*}{,247 } \\
\hline & Bazen & 3,60 & 970 & & \\
\hline & Hiçbir Zaman & 3,70 & 857 & & \\
\hline \multirow[t]{3}{*}{ Finansal Yönetim } & Her Zaman & 3,33 & ,731 & \multirow{3}{*}{2,589} & \multirow{3}{*}{,077 } \\
\hline & Bazen & 3,44 & ,762 & & \\
\hline & Hiçbir Zaman & 3,64 & ,619 & & \\
\hline
\end{tabular}

\section{$* \mathbf{p}<0.05$}

Tablo 8'de ANOVA testine göre katılımcıların Boş Zaman Değerlendirme Güçlüğü Çekme Durumu ile Serbest Zaman Engelleri İle Baş Etme Stratejileri Ölçeği (SZEBSÖ) puanlarında sadece "Beceri Kazanma Stratejileri" alt boyutunda anlamlı farklılık olduğu $(\mathrm{p}<0.05)$ fakat diğer alt boyutlarda anlamlı farklılık olmadığı belirlenmiştir ( $\mathrm{p}>0.05)$.

\section{Tartışma ve Sonuç}

$\mathrm{Bu}$ çalışmanın amacı, üniversite öğrencilerinin rekreatif faaliyetlere katılımını engelleyen faktörler ile baş etme stratejilerinin çeşitli demografik değişkenlere göre karşılaştırmalı incelenmesidir. Bu amaç doğrultusunda belirlenen örneklem grubunun \%75'inin erkek, \%55,2' sinin 21-25 yaş grubunda olduğu, \%42,0'ının 1. sinıf öğrencisi olduğu, \%53.7'sinin normal refah düzeyine sahip olduğu, \%84'ünün spor yaptığı, \%47'sinin normal haftalık boş zaman süresine sahip olduğu ve \%70.7'sinin boş zamanlarını değerlendirirken bazen güçlük çektiği belirlenmiştir.

Araştırmada katılımcıların cinsiyet değişkenine göre serbest zaman engelleri ile baş etme stratejileri incelendiğinde sadece "Beceri Kazanma Stratejileri" alt boyutunda anlamlı farkl1lık olduğu belirlenirken, ortalama değerleri dikkate alındığında bu anlamlı farkın erkek katılımcılardan kaynaklandığı ve erkek katılımcıların kadın katılımcılara göre "Beceri Kazanma Stratejileri” alt 
boyutunda serbest zaman engelleri ile daha iyi baş edebildiği sonucuna varılmıştır. Kadın ve erkeklerin toplum içinde karşılaştıkları olayların farklılığı bu durumu etkilediğini söyleyebiliriz. Fakat Koca vd. (2009) Türk toplumundaki kadınların sosyal sınıf bağlamında ele alarak engelleri ve bu engellerle baş etme stratejilerini inceledikleri çalışmalarında kişilerarası engellerden biri olan aileye ilişkin sorumlulukların kadınların serbest zaman katılımını etkilediği ve bu engele karşı kadınların geliştirdiği baş etme stratejilerinin ise; aile bireyleri ve sosyal çevrelerinden aldıkları onay olarak belirlemişlerdir. Ayrıca Karaca ve Lapa (2016) tarafından yapılan çalışmada bulgularımızın tersine cinsiyetin serbest zaman engelleri ile baş etme stratejilerinde anlamlı bir farklılık yaratan değişken olmadığı sonucuna ulaşılmıştır.

Katılımcıların spor yapma durumu değişkenine göre yapılan analiz sonuçlarına göre ise spor yapan bireylerin "Beceri Kazanma Stratejileri" alt boyutuna ve ölçek toplam puanına göre anlamlı farklılık gösterdiği belirlenmiştir. Yaş değişkenine göre ise katılımcıların serbest zaman engelleri ile baş etme stratejileri arasında anlamlı bir farklılık olmadığı ortaya çıkmıştır. Bu sonuç, Ayhan vd. (2018) tarafından serbest zaman tatmini ile ilgili yaptıkları araştırmanın bulguları ile paralellik göstermemektedir. Ayhan vd. (2018) çalışmasının yaş grupları ile çalışmamızın yaş grupları benzerlik göstermektedir. Çalışmaya göre yaş arttıkça serbest zaman tatminin arttığı belirlenmiştir. Fakat Güler ve ark. (2019) tarafından beden eğitimi ve spor yüksekokulu öğrencileri üzerine yapılan çalışmada da, çalışmamız ile benzer bir şekilde serbest zaman engelleri ile yaş arasından anlamlı farklılık bulunmamıştır. Bu sonuç bireylerin serbest zaman deneyimleri arttıkça engeller ile baş etme stratejilerinin de geliştiği ve bu anlamda daha rahat oldukları şeklinde yorumlanabilir.

Araştırmada serbest zaman engelleri ile baş etme stratejileri ile refah düzeyi arasında anlamlı bir farklılık belirlenemezken, Gratton (2000) yaptı̆̆ katılımındaki en önemli faktörün "para" olduğunu belirtmiştir. Ayrıca Emir vd. (2012) tarafından üniversite öğrencilerine yapılan çalışmada da "Bireysel Psikoloji" alt boyutunda gelir düzeyi ile anlamlı farklılık olduğu belirlenmiştir. Solakomur vd. (2019)'un yapmış olduğu çalışmada ise refah seviyesine göre anlamlı bir farklılık bulunmamış, bu sonuç araştırmanın bulguları ile benzerlik göstermektedir.

Çalışmamızdaki bir diğer önemli sonuçta boş zaman değerlendirme güçlüğü çekme durumu ile serbest zaman engelleri ile baş etme stratejileri ölçeği (SZEBSÖ) puanlarında sadece "Beceri Kazanma Stratejileri" alt boyutunda anlamlı farklılık olduğu $(\mathrm{p}<0.05)$, fakat diğer alt boyutlarda anlamlı farklılık olmadığı belirlenmiştir. Bu sonuçla serbest zaman değerlendirme güçlüğü çekmeyen bireylerde serbest zaman engelleri ile baş etme stratejilerini beceri kazanma stratejileri dışındaki alt boyutlarda geliştirebildikleri olarak yorumlanabilmektedir.

Sonuç olarak üniversite öğrencilerinde, katılımcıların cinsiyet, sınıf, sportif etkinliklere katılım durumu ve boş zaman değerlendirme güçlüğü çekme durumlarına göre, yani sosyo demografik özelliklere göre serbest zamanlarında karşılaştıkları engeller ile baş etme stratejileri farkl1l1k gösterebilmektedir. Özellikle spor yapma durumlarına göre ve boş zaman değerlendirme güçlüğü çekme durumlarına göre farklılıkların daha fazla olduğu söylenebilir. Bireylerin serbest zaman engelleri ile baş etme stratejileri ile ilgili çalışmaların nitel olarak ayrıntılı şekilde incelenerek artmas1 gerekmektedir.

\section{Kaynakça}

Ayhan, C., Eskiler, E., \& Ekinci, N. E. (2018). Extreme Sporcuların Serbest Zaman Tatmin Düzeylerinin Çeşitli Değişkenler Açısından İncelenmesi. In International Academic Sport Research Congress (134-141).

Beggs, B.A., Elkins, D.J., \& Powers, S. (2005). Overcoming barriers to participation in campus recreational sports. Recreational Sports Journal, 29(2),143-155. 
Crawford, D.W., Jackson, E.L., \& Godbey, G. (1991). A hierarchical model of leisure constraints. Leisure Sciences, 13(4), 309- 320.

Çuhadar, A., Demirel, M., Er, Y., \& Serdar, E. (2019). Lise Öğrencilerinde Boş Zaman Yönetimi Ve Gelecek Beklentisi İlişsisi. Journal Of International Social Research, 12(66), 1498- 1505.

Demirel, M., \& Harmandar, D. (2009). Üniversite öğrencilerinin rekreasyonel etkinliklere katılımlarında engel oluşturabilecek faktörlerin belirlenmesi. Uluslararası İnsan Bilimleri Dergisi, 6(1), 838-846.

Elkins, D.J. (2004). Levels of perceived constraint: A comparative analysis of negotiation strategies in campus recreational sports. Unpublished Doctoral Thesis. Indiana University.

Emir, E., Öncü, E., \& Gürbüz, B. (2012). Rekreatif Etkinliklere Katılımın Önündeki Engellerin Belirlenmesi: Üniversite Öğrencileri Örneği Examination of Constraints to Leisure Activities in Turkish University Students. Journal of Human Sciences, 14(4), 3895-3904.

Er, Y., Koç, M. C., Demirel, M., \& Çuhadar, A. (2019). The Meaning Of Leisure And Life Satisfaction: The Sample Of University Students. International Journal of Leisure and Life Satisfaction: The Sample of University Students, 6(2), 2-3.

Gratton, C., (2000). Economics Of Sport And Recreation”, Sport Press.

Güler, C., Demirel, H.,D., Çakır, V., O. \& Budak, D. (2019). Serbest Zaman Engelleri ile Baş Etme Stratejileri: (Üniversite Öğrencileri Örneği). 2. Uluslararası Rekreasyon ve Spor Yönetimi Kongresi, 11 - 14 Nisan 2019. 45-48.

Güngörmüş, H. A., Yenel, F., \& Gürbüz, B. (2014). Examination of recreational motives of individuals: Demographic differences Bireyleri rekreasyonel egzersize güdüleyen faktörlerin belirlenmesi: Demografik farklılıklar. Journal of Human Sciences, 11(1), 373-386.

Gürbüz, B. \& Henderson, K. (2014). Leisure activity preferences and constraints to leisure: perspectives from Turkey", World Leisure Journal, 56(4), 300-316.

Hubbard, J., \& Mannell, R.C. (2001). Testing competing models of the leisure constraint negotiation process in a corporate employee recreation setting. Leisure Sciences, 23(3),145-163.

Jackson, E.L. \& Scott, D. (1999). Constraints to leisure. In E.L. Jackson \& T.L. Burton, Leisure Studies: Prospects for 21st century (pp. 312-323). State College, PA: Venture Publishing.

Jondeau, E. \& Rockinger, M. (2003). Conditional volatility, skewness, and kurtosis: existence, persistence, and comovements. Journal of Economic Dynamics \& Control, 27, 1699 - 1737.

Kara, F. M., Gürbüz, B., \& Sarol, H. (2018). Yetişkinlerde serbest zamanda sıkılma algısı, algılanan sosyal yetkinlik ve benlik saygısı düzeyinin incelenmesi. Int J Sport, Exer \& Train Sci, 2018, 4(4), 113-121.

Karaca, A. A., \& Yerlisu Lapa, T. (2016). Serbest zaman katılımı, psikolojik iyi olma ve serbest zaman engelleri ile baş etme stratejilerinin üniversite öğrencileri üzerinde incelenmesi. Journal of Human Sciences, 13(2), 3293-3304. http://dx.doi.org/10.14687/jhs.v13i2.3778

Koca, C., Henderson, K.A., Asci, F.H., \& Bulgu, N. (2009). Constraints to leisure-time physical activity and negotiation strategies in turkish women. Journal of Leisure Research, 41(2), 225-251.

Lapa, T. Y., \& Köse, E. (2018). Serbest Zaman Engelleri ile Engellerle Baş Etme Stratejileri arasındaki İlişkinin İncelenmesi: Keşifsel Bir Çalışma. CBÜ Beden Eğitimi ve Spor Bilimleri Dergisi, 13(2), 356-375. 
Özdilek, Ç., Demirel, M. \& Harmandar, D. (2007). Dumlupınar ve Sakarya Üniversitelerinde Öğrenim Gören Beden Eğitimi ve Spor Yüksekokulu Öğrencilerinin Boş Zaman Etkinliklerine Katılım Nedenleri ve Düzeylerinin Araştırılması", Uluslararası Insan Bilimleri Dergisi, 4(2), 1-13.

Rhodes, R.E. \& Dean, R.N. (2009) Understanding physical inactivity: Prediction of four sedentary leisure behaviors. Leisure Sciences, 31(2): 124-135.

Sarol, H., \& Çimen, Z. (2017). Why people participate leisure time physical activity: a Turkish perspective. Pamukkale Spor Bilimleri Dergisi, 8(1). 63-72.

Songün, Y, Katkat., Budak, D. (2015). Türkiye'deki ulusal spor federasyonlarının doping kontrol uygulamalarının değerlendirilmesi. SPORMETRE Beden Eğitimi ve Spor Bilimleri Dergisi, 13(2), 93-102.

Soyer, F., Yıldız, N. O., Harmandar Demirel, D., Serdar, E., Demirel, M., Ayhan, C., \& Demirhan, Ö. (2017). Üniversite öğrencilerinin rekreatif etkinliklere katılımlarına engel teşkil eden faktörler ile katılımcıların yaşam doyumları arasındaki ilişkinin incelenmesi. Journal of Human Sciences, 14(2), 2035-2046.

Tel, F. D. \& Sarı, T.(2016).Üniversite öğrencilerinde öz duyarlılık ve yaşam doyumu. Abant İzzet Baysal Üniversitesi Eğitim Fakültesi Dergisi, 16(1), 292-304.

Üstün, Ü.D. (2013). Beden eğitimi ve spor yüksekokulu ögrencilerini rekreatiffaaliyetlere katılmaya motive eden faktörlerin araştırılması. Yayımlanmamış Yüksek Lisans Tezi. Dumlupınar Üniversitesi. Sağlık Bilimleri Enstitüsü.

Yerlisu Lapa, T. (2014). Leisure negotiation strategies scale: A study of validity and reliability for university students. South African Journal for Research in Sport, Physical Education and Recreation, 36(3), 201-215. 